\title{
Institutionalism is following the mentally ill into the community
}

\author{
Tony Whitehead
}

During my first acquaintanceship with psychiatric hospitals many years ago I came across the suicide card. This was a red card with a warning that the patient was suicidal, signed by the nurse or attendant in charge, to show where the responsibility fell if the patient attempted, or succeeded in, suicide. Many hospitals at that time had developed a special system for dealing with patients considered to be suicidal. This consisted of sitting the patients at risk in a circle, with one nurse in the centre and one on the outside of the circle. There they sat, only rising to return to bed. They were fed and watered in the circle and, when necessary, escorted to the tollet by the outside nurse.

The suicide card has been the symbol of institutionalism for me ever since that first encounter. The causes and symptoms of institutionalism are now so well known that they have almost been forgotten but other minor symbols followed the suicide card into my personal cartoon image of the condition. These included the dreadfully ritualistic reports made out regularly on each patient for the Board of Control and the many local rules and systems devised following some local problem. The most dramatic example of the latter was the building of Claybury Hospital in Essex with extremely wide corridors. It was built with such corridors following a fire elsewhere, the idea being that fire engines could easily drive down the corridors if necessary.

Most psychiatrists have spent their lives battling against institutionalism and over the years have created, with the help and enthusiasm of nurses and other professionals within the psychiatric service, in-patient regimes that discouraged institutionalism and encouraged the establishment of care in the community. Recently care in the community has become new and official, and the symbols and the dangers of institutionalism are coming back, not into the institutions but into the community.

Care plans for patients, allocating patients a key worker and having regular review meetings all sound sensible and helpful developments.
Even an at risk register does not appear to be all bad. Unfortunately all this is yet another manifestation of institutionalism. Its origins grew out of the scandals associated with a number of tragedies and it is a method of insuring that someone will be to blame if these tragedies, which of course must never happen again, do happen again. The tragedies which occur have always occurred whatever the system and this has been beautifully illustrated by Douglas Bennett (1995).

Good psychiatric practice has always included keeping a friendly eye upon individuals who are considered to be at risk and this has been done by all the team, with each taking a special interest in certain patients as now is expected of the key worker. However, this has been done discreetly and with the minimum of intrusion. Now the eye is an official eye and the intrusion compulsory. It also places responsibilities upon the key worker that are onerous and sometimes very difficult to deal with. No account is taken of this extra work and responsibility. I do not think there is any doubt that such control and intrusion will have side-effects upon the patient, much like those of the institutions in the past.

The system for dealing with psychiatric patients in the community only applies to psychiatric services. It does not apply to the rest of medicine, not even to geriatric practice, where there are clearly large numbers of elderly people in the community and at risk. Of course the elderly person who has come in contact with psychiatry will have the system applied to him or her but not otherwise. Once again those labelled mentally ill are being singled out and discriminated against and, as always, this is being done with the very best intentions.

\section{Reference}

BENNETT, D. (1995) No lion can him fright. Psychiatric Bulletin, 19, 565-566.

Tony Whitehead, Brighton General Hospital, Elm Grove, Brighton BN2 3EW 